Document downloaded from:

http://hdl.handle.net/10251/153695

This paper must be cited as:

Bandinelli, C.; Lambiase, B.; Tabanelli, T.; De Maron, J.; Dimitratos, N.; Basile, F.; Concepción Heydorn, P.... (2019). A study of the oxidehydration of 1,2-propanediol to propanoic acid with bifunctional catalysts. Applied Catalysis A General. 582:1-9. https://doi.org/10.1016/j.apcata.2019.05.036

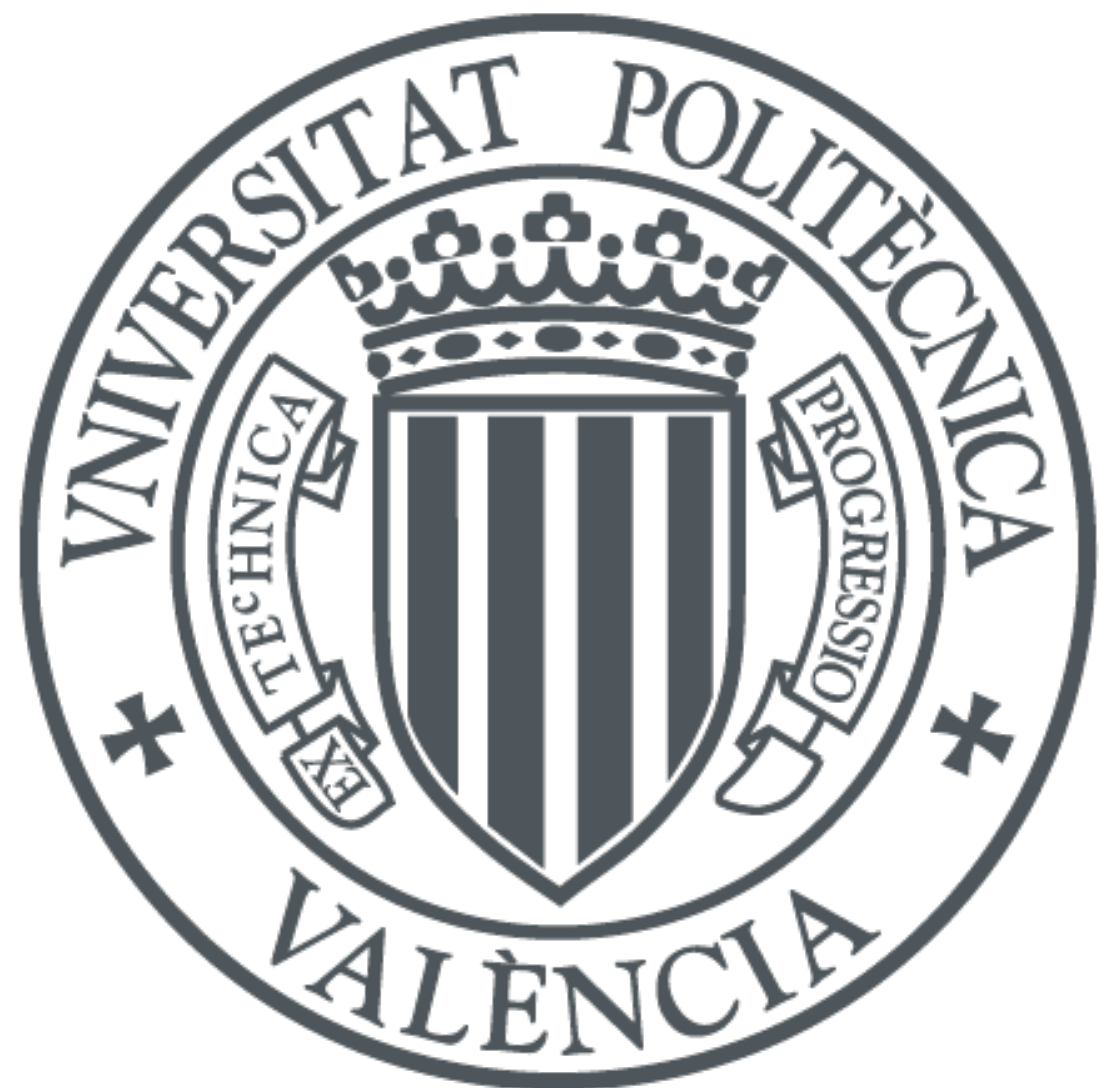

The final publication is available at

https://doi.org/10.1016/j.apcata.2019.05.036

Copyright Elsevier

Additional Information 


\title{
The oxidehydration of 1,2-propanediol to propanoic acid with bifunctional catalysts
}

Claudia Bandinelli, ${ }^{1,2}$ Tommaso Tabanelli, ${ }^{1}$ Jacopo De Maron, ${ }^{1,2}$ Nikolaos Dimitratos, ${ }^{1}$ Francesco Basile, ${ }^{1}$ Patricia Concepcion, ${ }^{3}$ Jose Manuel Lopez Nieto, ${ }^{3}$ Fabrizio Cavani ${ }^{1,2, *}$

${ }^{1}$ Dipartimento di Chimica Industriale “Toso Montanari”, Alma Mater Studiorum Università di Bologna, Viale Risorgimento 4, 40136 Bologna, Italy

${ }^{2}$ Consortium INSTM, Firenze, Research Unit of Bologna

${ }^{3}$ Instituto de Tecnología Química, Universitat Politecnica de Valencia-Consejo Superior de Investigaciones Científicas, Avenida de los Naranjos s/n, 46022, Valencia, Spain

\begin{abstract}
The gas-phase oxidehydration (ODH) of 1,2-propanediol to propionic acid has been studied as an intermediate step in the multi-step transformation of biosourced glycerol into methylmethacrylate. The reaction involves the dehydration of 1,2-propanediol into propionaldehyde, which occurs in the presence of acid active sites, and a second step of oxidation of the aldehyde to the carboxylic acid. The two reactions were carried out using a cascade strategy and multifunctional catalysts, made of $\mathrm{W}-\mathrm{Nb}-\mathrm{O}, \mathrm{W}-\mathrm{V}-\mathrm{O}$ and $\mathrm{W}-\mathrm{Mo}-\mathrm{V}-\mathrm{O}$ hexagonal tungsten bronzes, the same systems which are also active and selective in the ODH of glycerol into acrylic acid. Despite the similarities of reactions involved, the ODH of 1,2-propanediol turned out to be less selective than glycerol ODH, with best yield to propanoic acid no higher than $13 \%$, mainly because of the parallel reaction of oxidative cleavage, occurring on the reactant itself, which led to the formation of $\mathrm{C}_{1}-\mathrm{C}_{2}$ compounds.
\end{abstract}

Keywords: 1,2-propanediol; propionic acid; propionaldehyde; hexagonal tungsten bronze; tungsten oxide; oxidehydration 


\section{Introduction}

Propanediols (PD) are interesting bio-based building blocks for the synthesis of a variety of chemicals [1-3]. Both 1,2-PD and 1,3-PD can be obtained from biomass, e.g., by sugar fermentation or by chemo-catalytic hydrodeoxygenation (HDO) of glycerol or lactic acid [4-10]. In the latter case, various catalytic systems are known to catalyse efficiently the HDO to 1,2-PD, whereas the synthesis of 1,3-PD is more challenging, requiring catalysts based on $\mathrm{Rh}(\mathrm{Ir}) / \mathrm{Re}$ in order to achieve acceptable selectivity.

Amongst the various compounds which can be synthesized from 1,2-PD, eg, propionaldehyde by dehydration [11-14], propanol [15], and pyruvaldehyde [16], and propanoic acid (PAC) [17-19], the latter might be the intermediate for the synthesis of bio-based methacrylic acid (MAA) and methylmethacrylate (MMA), the monomer for polymethylmethacrylate [20-22]. The glycerol-toMAA pathway would thus include the following steps:
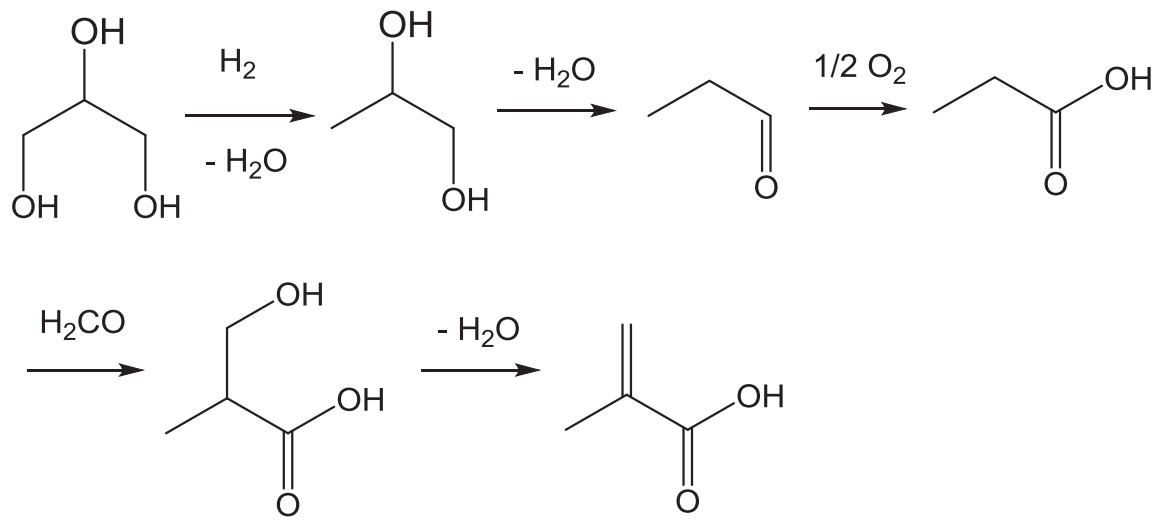

Scheme 1. The multi-step strategy for the synthesis of MAA from glycerol.

The second step (i.e., the acid-catalysed dehydration of 1,2-PD) and the third step (the oxidation of PAL to PAC) may be carried out with a one-pot process by using a single but bifunctional catalyst, showing both acid and oxidizing properties. 
Indeed, it is well-know that on acidic catalysts, 1,2-PD can also transform into acetone and allylic alcohol, depending on which hydroxyl group is involved into the dehydration process $[11,13,23]$. Referring to literature, it is interesting to note that PAL generally is the main dehydration product with most of the acid materials so far studied for 1,2-PD dehydration. The latter behavior was explained by Zhang et al [11] on the basis of the mechanism reported in Scheme 2.

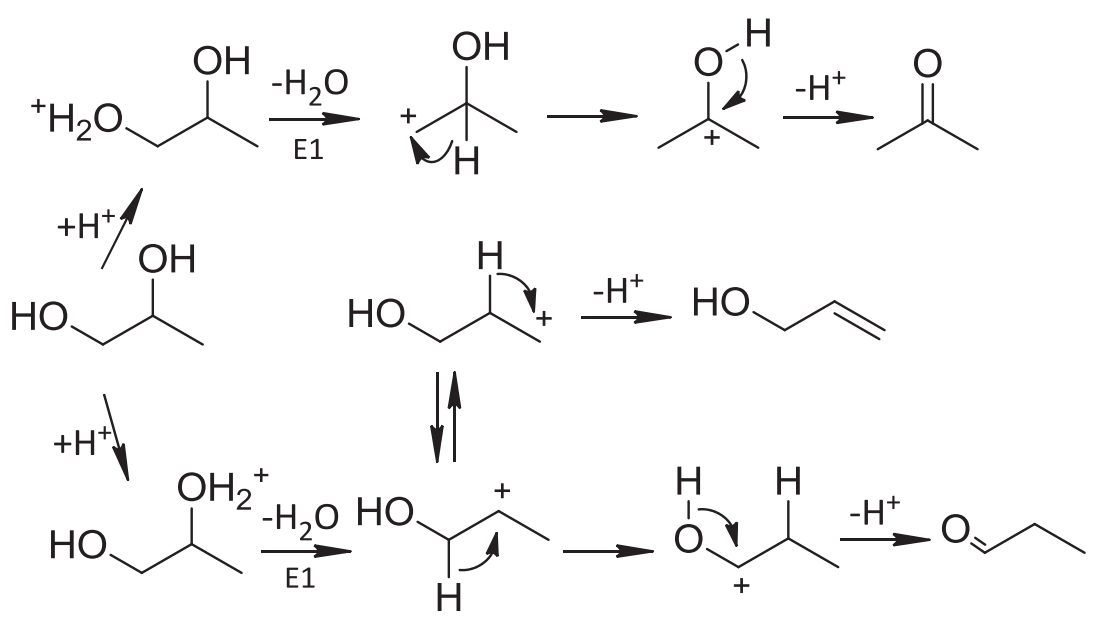

Scheme 2. 1,2-PD dehydration over solid acid catalysts.

1,2-diols are known to undergo the pinacol rearrangement to give the corresponding aldehyde [24], hence the authors proposed that protonation of either of the hydroxyl groups and rearrangement can generate three different reactive carbenium intermediates which yield acetone, PAL and allyl alcohol, respectively. The secondary carbenium ion, leading to PAL, is the more stable thus it is expected to have the higher concentration. Despite this, acid/base features of the catalysts might considerably influence 1,2-PD conversion [23]. In previous works, we reported about the reactivity of hexagonal tungsten bronzes (HTBs) for the oxidehydration of glycerol to acrylic acid, with intermediate formation of acrolein [25-31]. The glycerol-to-acrylic acid reaction is supposed to be similar to 1,2-PD-to-propanoic acid, because of the similar 
molecules and reaction steps involved, and HTB oxides appear to possess the proper acid properties to perform the selective dehydration of 1,2-PD to PAL, both in terms of acid strength and type of acid sites, where the preponderance of Brønsted sites was proved to be beneficial for the reaction. Here we report about the use of HTBs for the ODH of 1,2-PD to PAC, via intermediate formation of PAL.

\section{Experimental}

\subsection{Catalyst Preparation}

$\mathrm{W}-\mathrm{V}-\mathrm{O}, \mathrm{W}-\mathrm{Nb}-\mathrm{O}$ and $\mathrm{W}-\mathrm{Mo}-\mathrm{V}-\mathrm{O}$ catalysts, with hexagonal tungsten bronze structure (HTB), were prepared hydrothermally at $175^{\circ} \mathrm{C}$ for $48 \mathrm{~h}$, according to a previously reported preparation procedure [25-27]. The catalysts precursors were finally heat-treated at $600^{\circ} \mathrm{C}$ for $3 \mathrm{~h}$ in an inert atmosphere. They will be named as WV-1, WNb-2 or WMoV-3.

A mixed oxide Mo-V-W-O catalyst, with $\mathrm{Mo} / \mathrm{V} / \mathrm{W}$ molar ratio of $8 / 2 / 0.5$, was prepared by coprecipitation from an aqueous solution (with ammonium heptamolybdate, ammonium metavanadate, and ammonium metatungstate; $\mathrm{pH}=$ 5). The dried material was finally heat-treated at $400^{\circ} \mathrm{C} 2 \mathrm{~h}$ in an inert atmosphere (with a BET surface area of $11 \mathrm{~m}^{2} \mathrm{~g}^{-1}$ ).

\subsection{Characterization of catalysts}

BET catalyst surface areas, determined by multi-point $\mathrm{N} 2$ adsorption at $-176^{\circ} \mathrm{C}$, were obtained in a Micromeritics ASAP 2000 instrument.

Powder X-ray diffraction (XRD) patterns were achieved in a PANalytical $\mathrm{X}$ 'Pert PRO diffractometer, with a monochromatic $\mathrm{CuK} \alpha$ source and operated at $40 \mathrm{kV}$ and $30 \mathrm{~mA}$ was used.

FTIR spectra of adsorbed 1,2-PD were recorded with a Nexus (Thermo) 8700 FTIR spectrometer using a conventional quartz infrared cell connected to a vacuum dosing system. All catalysts have been activated in situ in a flow of air 
at $300^{\circ} \mathrm{C}$ for $2 \mathrm{~h}$ followed by vacuum treatment $\left(10^{-5} \mathrm{mbar}\right)$ at $350^{\circ} \mathrm{C}$ for $1 \mathrm{~h}$ and further cooling down to $25^{\circ} \mathrm{C}$ in vacuum. At $25^{\circ} \mathrm{C}, 0.5 \mathrm{mbar}$ of 1,2-PD has been co-adsorbed with 1.7 mbar of $\mathrm{O}_{2}$. Reaction intermediate species has been monitored by IR spectroscopy at different temperatures in the 25 to $240^{\circ} \mathrm{C}$ range, analyzing both surface adsorbed species as well as gas-phase species. For the last case, re-adsorption of gas phase species promoted by cooling down the IR pellet has been done, and the corresponding IR spectra have been labelled as "cooled-down" spectra.

\subsection{Catalytic tests}

Gas-phase reactivity experiments were performed using a continuous flow reactor made of glass. A catalyst amount ranging from 0,1 to $0,5 \mathrm{~g}$ was loaded in powder form. The time factor was calculated as the ratio between catalyst volume $(\mathrm{mL})$ and total gas flow $(\mathrm{mL} / \mathrm{s})$, the latter being measured at room temperature. It was varied by keeping constant the total gas flow and changing the catalyst amount. Inlet feed composition was also changed according to the desired compositions. If not differently specified, the catalytic results were obtained after a reaction time of $60 \mathrm{~min}$.

The effluent stream was bubbled through two/three in-series abatement devices filled with water, kept at $0-2^{\circ} \mathrm{C}$. After the abatement step, where the condensable organic molecules were collected, the gaseous stream still containing oxygen and carbon oxides, was fed into an automatic sampling system for on-line gas chromatography (GC-TCD) analysis. The aqueous solution was analyzed off-line by GC-FID analysis, using a reference standard (valeric acid). Both gas chromatographic analyses were performed with a Hewlett-Packard 5890 instrument, equipped with either FI and TC detectors. A semi-capillary ZB-FFAP (nitroterephthalic acid modified polyethylene glycol) column was used for the separation of condensed compounds, whereas two wide-bore columns were used for the separation of non-condensable products: a 
Mol Sieve 5A Plot for $\mathrm{O}_{2}$ and $\mathrm{CO}$, and a Silica Plot for $\mathrm{CO}_{2}$. Compounds were identified by means of both GC-MS analysis and the injection of pure reference standards for the comparison of retention times. Conversion, yields and selectivities were calculated by the following formulas:

$\mathrm{X}_{\mathrm{R}}=\left[\left(\mathrm{mol} \mathrm{C}_{\mathrm{Rin}}-\mathrm{mol} \mathrm{C}_{\mathrm{Rout}}\right) / \mathrm{mol} \mathrm{C} \mathrm{Rin}_{\mathrm{Rin}}\right]^{* 100}$

$\mathrm{Y}_{\mathrm{i}}=\left(\mathrm{mol} \mathrm{C}_{\text {iout }} / \mathrm{mol} \mathrm{C}_{\mathrm{iin}}\right) * 100$

$\mathrm{S}_{\mathrm{i}}=\left(\mathrm{Y}_{\mathrm{i}} / \mathrm{X}_{\mathrm{R}}\right)^{*} 100$

In particular, mol $\mathrm{C}_{\mathrm{Rin}}$ and mol $\mathrm{C}_{\mathrm{Rout}}$ represent the moles of $\mathrm{C}$ atoms of the

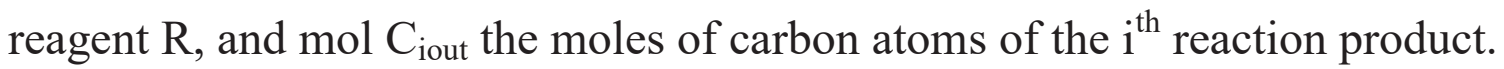

A few unknown compounds were also eluted in the GC column; we attributed them the same response factor as for the corresponding known compound with the closest retention time. In figures, all minor compounds are grouped together under the heading "Others". Heaviest compounds not eluted from the GC column (left as residues on both the catalyst surface and reactor walls) were quantified as the remainder of the total carbon balance and labeled as "Heavy compounds". Carbon balance was calculated by the formula:

$\mathrm{C}_{\text {bal }}=\left[\left(\Sigma Y_{\mathrm{i}}\right) / \mathrm{X}_{\mathrm{R}}\right] * 100$.

Carbon loss $=1-\mathrm{C}_{\mathrm{bal}}$

\section{RESULTS AND DISCUSSION}

\subsection{Physico-chemical characteristics of catalysts}

Table 1 summarizes the characteristics of catalysts used. They showed surface area in the range of 9 to $40 \mathrm{~m}^{2} \mathrm{~g}^{-1}$, depending on the composition and the catalyst preparation procedure.

The tungsten-based metal oxides (i.e. WV-1, WNb-2 and WVMo-3) showed the typical XRD diffraction patterns of the hexagonal tungsten bronze (HTB) phase (JCPDS: 85-2460) (Fig. 1, patterns a to c) [27]. 
The MoVW-4 sample presented diffraction peaks similar to those reported previously for catalysts presenting a $\mathrm{Mo}_{5} \mathrm{O}_{14}$-type structure [32], i.e., $\mathrm{Mo}_{5} \mathrm{O}_{14}$ oxide (JCPDS: 12-0517) having a tetragonal lattice cell (Fig. 1, pattern d).

According to previous results, $\mathrm{WNb}-2$ showed only acid characteristics, whereas WV-1 and WVMo-3 showed both acid and redox characteristics [29]. On the other hand, sample MoVW-4 presented only redox properties, with negligible acid characteristics.

Table 1. Physico-chemical characteristics of catalysts

\begin{tabular}{lllll}
\hline Sample & $\begin{array}{l}\text { Catalyst formal } \\
\text { stoichiometry }\end{array}$ & $\begin{array}{l}\text { Surface area } \\
\left(\mathrm{m}^{2} \mathrm{~g}^{-1}\right)\end{array}$ & ${\mathrm{TPD}-\mathrm{NH}_{3}{ }^{\mathrm{a}}}^{\mathrm{a}}$ & Ref. $^{\mathrm{b}}$ \\
\hline $\mathrm{WV}-1$ & $\mathrm{~W}_{1} \mathrm{~V}_{0.21}$ & 19 & 76 & 28 \\
$\mathrm{WNb}-2$ & $\mathrm{~W}_{1} \mathrm{Nb}_{0.20}$ & 28 & 121 & 26 \\
WVMo-3 & $\mathrm{W}_{1} \mathrm{~V}_{0.04} \mathrm{Mo}_{0.45}$ & 38 & 129 & 28 \\
MoVW-4 & $\mathrm{Mo}_{0.68} \mathrm{~V}_{0.23} \mathrm{~W}_{0.09}$ & 6 & 21 & 27 \\
\hline
\end{tabular}

TPD-NH3 in $\mu \mathrm{mol}_{\mathrm{NH} 3} \mathrm{~g}^{-1}$

\subsection{Reactivity tests}

First, we investigated 1,2-PD conversion with WNb-2 catalyst; for this catalyst we expect only acidic properties, therefore only the first step of the reaction, i.e., the dehydration of 1,2-PD into PAL, should occur. The introduction of $\mathrm{Nb}$ into $\mathrm{WO}_{\mathrm{x}}$ with HTB structure was previously proved to improve the acid properties of $\mathrm{WO}_{\mathrm{x}} \mathrm{HTB}$ oxide ${ }^{[5,6]}$, but the main positive effect was on its thermal stability. In Figure 2, 1,2-PD conversion on $\mathrm{WNb}-2$ is reported as a function of temperature; feed composition was the same as that previously employed for glycerol oxidehydration [26,27]: (mol \%) 1,2-PD/O $\mathrm{O}_{2} / \mathrm{H}_{2} \mathrm{O} / \mathrm{N}_{2}=2 / 4 / 40 / 54$. 


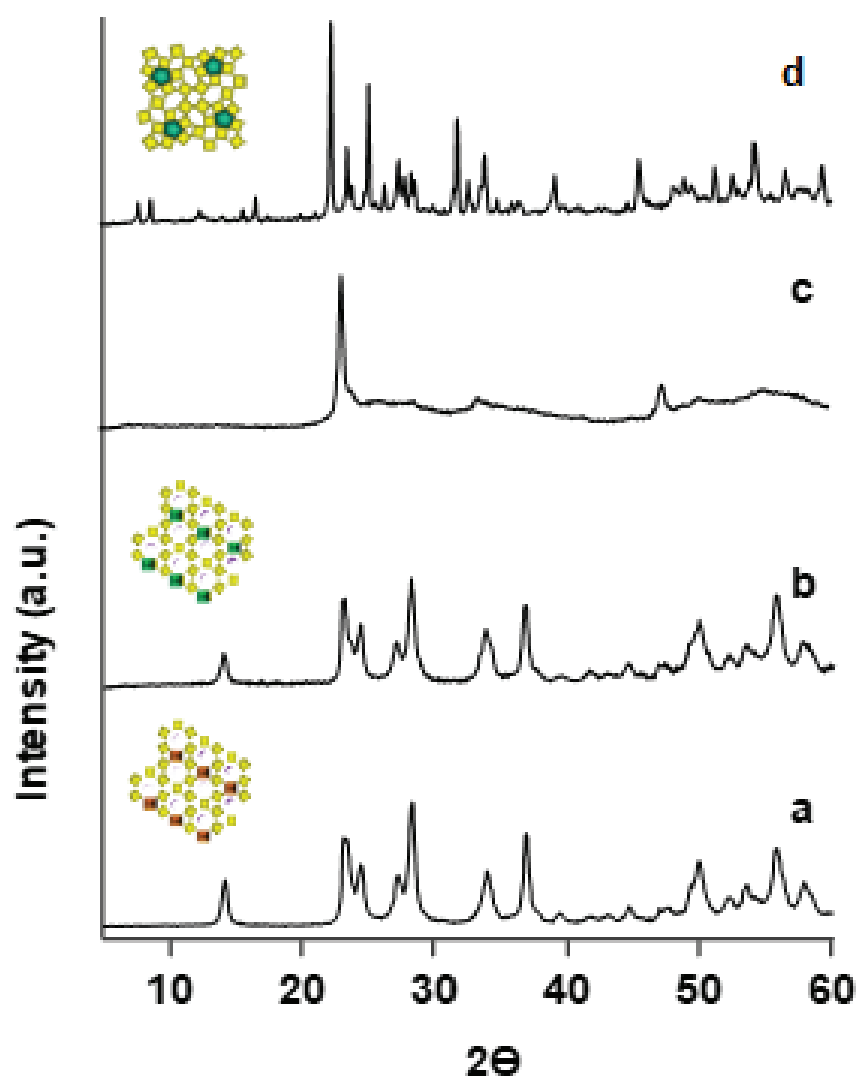

Figure 1. XRD patterns of catalysts. (a): WV-1; (b) WNb-2; (c) WVMo-3; (d) MoVW-4.

In the temperature range of $240-260^{\circ} \mathrm{C}, \mathrm{PAL}$ yields as high as $86 \%$ were obtained, whereas acetone and allylic alcohol yields were lower than 2\%. 1,2PD conversion was complete for temperature higher than $240^{\circ} \mathrm{C}$. For lower temperatures, the formation of heterocyclic acetals was observed, reported as "dioxolanes" in the graph. These molecules derive from a reversible bimolecular reaction between unconverted 1,2-PD and an aldehyde, this reaction being promoted by acid catalysts as well. In particular, three different species of dioxolanes were detected: 2-ethyl-4-methyl-1,3-dioxolane, 2,4-methyl-1,3dioxolane and 4-methyl-1,3-dioxolane, supposedly deriving from the condensation reactions between the glycol and PAL, acetaldehyde and formaldehyde respectively (Scheme 3). 


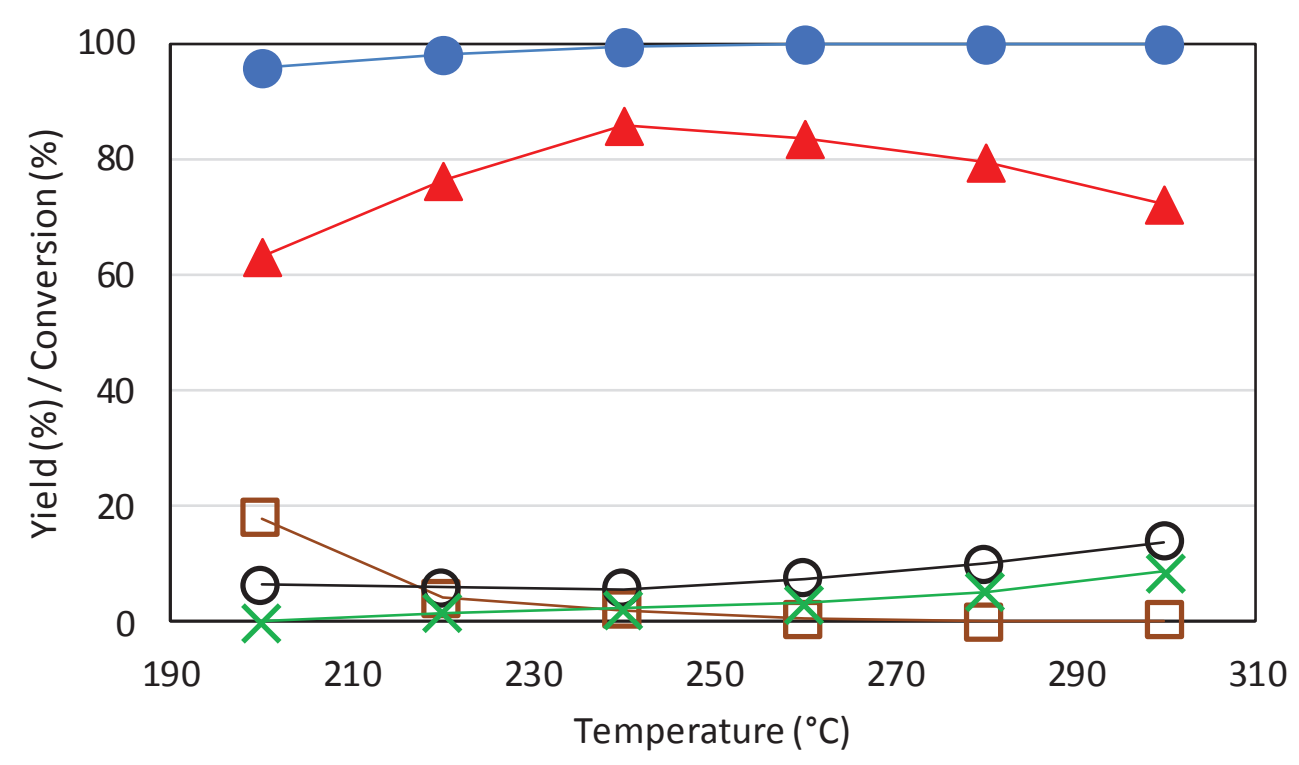

Figure 2. 1,2-PD conversion with $\mathrm{WNb}-2$ sample as a function of temperature.

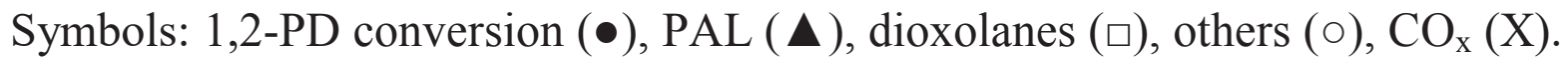
"Others" includes: acetaldehyde, acetone, acrolein, methacrolein, allylic alcohol, 1-PrOH, acetic acid, propionic acid, 2-methyl-2-pentenal and unknown compounds. Carbon loss was always less than 7\%. Reaction conditions: feed composition (mol\%): 1,2-PD/O $\mathrm{O}_{2} / \mathrm{H}_{2} \mathrm{O} / \mathrm{N}_{2}=2 / 4 / 40 / 54 ; \mathrm{W} / \mathrm{F}$ (time factor) $=0,01$ $\mathrm{g} * \min / \mathrm{ml}$.

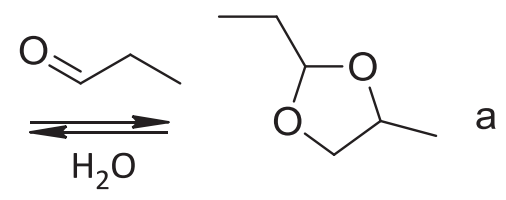<smiles>CC(O)CO</smiles><smiles>O=CCCCCCO</smiles><smiles>CC1COC(C)O1</smiles><smiles>O=CCOCC(=O)O</smiles><smiles>CC1COCO1</smiles>

Scheme 3. Formation of cyclic acetals from condensation between 1,2-PD and PAL, acetaldehyde and formaldehyde: a) 2-ethyl-4-methyl-1,3-dioxolane; b) 2,4-methyl-1,3-dioxolane; c) 4-methyl-1,3-dioxolane. 
Anyway, relatively higher yields into 2-ethyl-4-methyl-1,3-dioxolane (the acetal deriving from PAL) were obtained, whereas 2,4-methyl-1,3-dioxolane and 4methyl-1,3-dioxolane formed in minor amount. Dioxolanes formed in considerable amount at lower reaction temperatures and incomplete 1,2-PD conversion, as already observed for other catalytic systems [11,13], and the amount rapidly decreased while increasing temperature, mainly in favor of the corresponding aldehydes. PAL yield increased from $63 \%$ at $200^{\circ} \mathrm{C}$ to $86 \%$ at $240^{\circ} \mathrm{C}$. Above this temperature, PAL slowly decreased reaching a $72 \%$ yield at $300^{\circ} \mathrm{C}$, mainly in favor of the formation of carbon oxides, acetaldehyde, acetic acid, propionic acid and acrolein (reported as "others" in figure).

An experiment was performed feeding 1,2-PD without oxygen in the feed, at the temperature of $240^{\circ} \mathrm{C}$. In Table S1 the results obtained in the second hour of reaction are compared with those obtained with $\mathrm{O}_{2}$. Indeed, during the first hour a higher $\mathrm{C}$ loss was observed, while with oxygen $\mathrm{C}$ balance was always good. After two hours reaction, a yield of $87 \%$ to PAL was obtained, comparable to the result of the experiment carried out with oxygen. Overall, the selectivity to PAL did not significantly increase without oxygen in the feed. In fact, on one hand the amount of by-products deriving from oxidation reactions (carbon oxides, acetaldehyde, acetic acid, propionic acid and acrolein), as well as the amount of dioxolanes, were reduced; on the other hand, the formation of 2methyl-2-pentenal, deriving from the self-condensation of PAL, slightly increased.

These experiments confirmed that that $\mathrm{WNb}-2$ catalyst did not hold selective oxidation properties, since the formation of PAC was negligible.

We then tested the reactivity of HTB catalysts with either V or Mo in place of $\mathrm{Nb}$, in order to enhance the redox properties of the system and accelerate the oxidation of the intermediately formed PAL into PAC.

The influence of temperature on 1,2-PD conversion was investigated with WV-1 (Figure 3), in function of temperature. 


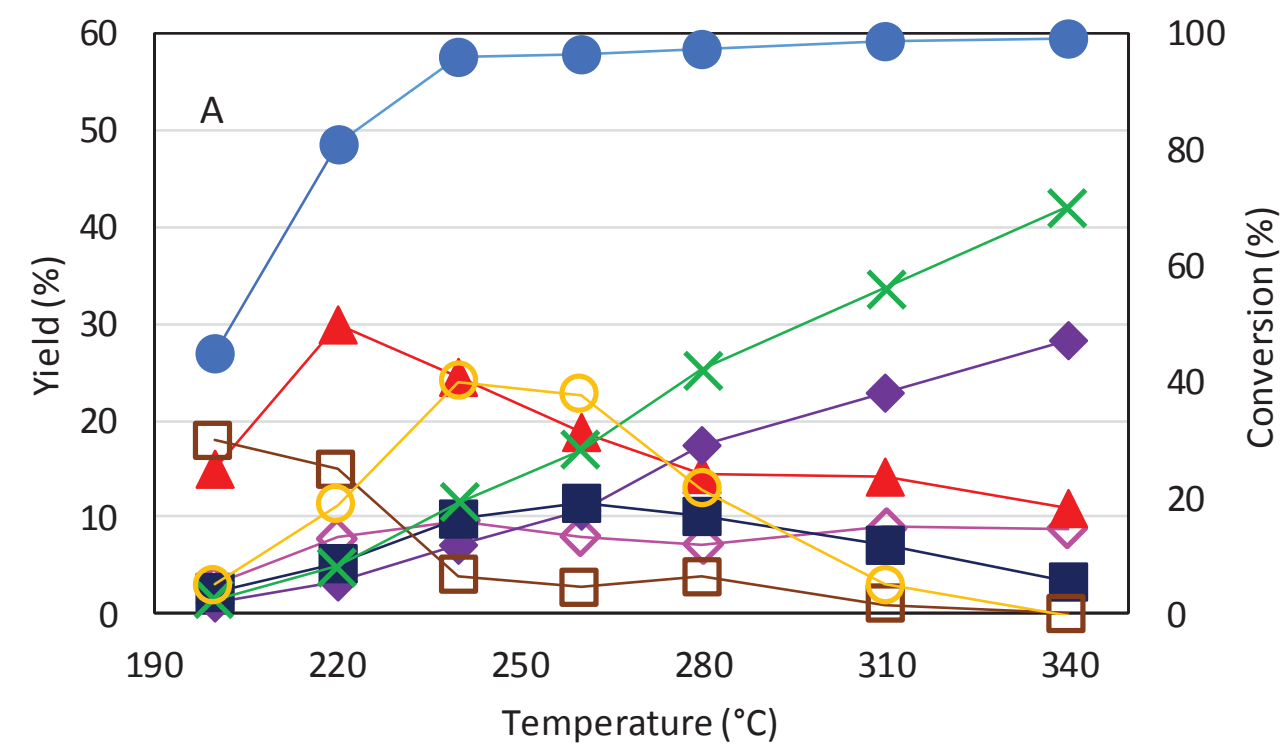

Figure 3. 1,2-PD conversion as a function of temperature with WV-1. Symbols: 1,2-PD conversion $(\bullet)$, PAL $(\boldsymbol{\Delta})$, dioxolanes $(\square)$, acetaldehyde $(\diamond)$, acetic acid $(\diamond)$ PAC ( $\square$ ) and carbon loss (०), $\mathrm{CO}_{\mathrm{x}}(\mathrm{X})$. Reaction conditions: feed composition (mol\%) 1,2-PD/ $\mathrm{O}_{2} / \mathrm{H}_{2} \mathrm{O} / \mathrm{N}_{2}=2 / 4 / 40 / 54 ; \mathrm{W} / \mathrm{F}$ (time factor) $=0,01$ g*min/ml.

The main reaction products were PAL, dioxolanes, acetaldehyde, acetic acid, propionic acid and carbon oxides. Minor products, reported as "others" in the graph, and showing a maximum of $6 \%$ yield, were allylic alcohol, acetone, 1propanol, acrolein, methacrolein and acrylic acid. Referring to the dehydration step of the process, WV-1 was also able to selectively dehydrate 1,2-PD into PAL, showing very low yields to acetone and allylic alcohol. Despite this fact, the maximum yield to PAL obtained was about $30 \%$ at $220^{\circ} \mathrm{C}$. For temperatures lower than $240^{\circ} \mathrm{C}$ and incomplete 1,2-PD conversion, dioxolanes formed in considerable amount, as already observed with $\mathrm{WNb}-2$. Increasing the temperature, dioxolanes yield rapidly decreased mainly in favor of PAL and acetaldehyde. Then, a further increase of temperature made PAL yield progressively decrease, with acetic acid and carbon oxides rapidly increasing and becoming the main reaction products for temperatures higher than $280^{\circ} \mathrm{C}$ whereas PAC formed in minor amount only, with a maximum yield of $11 \%$ at 
$260^{\circ} \mathrm{C}$. Arguably, acetic acid may generate from the oxidation of acetaldehyde while the latter might originate directly from 1,2-PD, by means of a $\mathrm{C}-\mathrm{C}$ oxidative cleavage, but also from the intermediate PAL. Together with acetaldehyde, the $\mathrm{C}-\mathrm{C}$ cleavage reaction might also generate a molecule of formaldehyde, which can be further oxidized to formic acid or $\mathrm{CO} / \mathrm{CO}_{2}$, as reported in Scheme 4. Unfortunately, formaldehyde and formic acid could not be detected with our analytical system. Anyway, as to ascertain their presence, an analysis of a reaction sample with HPLC-RID was made, and their formation was confirmed. Finally, a contribution to $\mathrm{C}_{1}$ and $\mathrm{C}_{2}$ compounds deriving from PAC cannot be excluded as well.

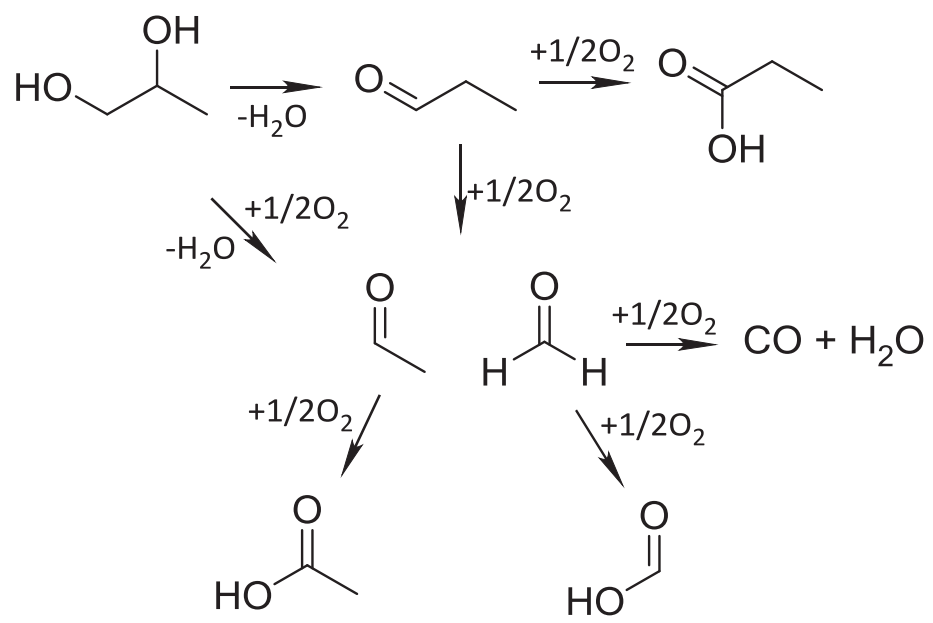

Scheme 4. Possible reaction network for 1,2-PD conversion with WV-1 catalyst.

It is also interesting to compare results of 1,2-PD conversion with those obtained by feeding glycerol. In Figure S1. Experiments were carried out using the same reaction conditions as those used with 1,2-PD. All in all, it is important to mention that with glycerol the transformation into the corresponding acid (acrylic acid) prevailed over the formation of acetaldehyde and acetic acid in a certain range of temperature, and the maximum yield of $26 \%$ into acrylic acid 
was obtained at $290^{\circ} \mathrm{C}$. On the other hand, a greater amount of carbon oxides formed.

At this point, PAL was fed with WV-1 catalyst in order to check whether this catalyst could perform the selective oxidation of the aldehyde into PAC (results are reported in Figure S2). PAL converted into propionic acid, acetaldehyde, acetic acid, and carbon oxides. Moreover, the formation of a remarkable quantity of heavy compounds, especially deposited on the surface of the reactor, was also observed. Hence, the carbon loss shown in Figure S2 is mainly attributed to the formation of heavy compounds. PAL conversion raised from about $40 \%$ at $240{ }^{\circ} \mathrm{C}$ up to $80 \%$ at $280^{\circ} \mathrm{C}$. PAC showed the best selectivity of $37 \%$ at the temperature of $260^{\circ} \mathrm{C}$. Nevertheless, this selectivity value was limited at lower temperatures by the formation of heavy compounds, arguably deriving from the condensation of the aldehyde itself, promoted by the acidity of the catalyst. The redox ability of the catalyst appeared to be largely affected by the reaction temperature and, presumably, at lower temperatures the rate of the oxidation might be slower, and this fact could favor the condensation reactions. The $\mathrm{C}$ loss decreased while increasing the temperature; on the other hand, the formation of a considerable amount of $\mathrm{C}_{1}$ and $\mathrm{C}_{2}$ compounds, deriving from the oxidative cleavage of PAL, was also observed (Scheme 5).

The reactivity of the catalyst belonging to the family of HTB oxides consisting of the tricomponent $\mathrm{W}-\mathrm{Mo}-\mathrm{V}-\mathrm{O}$ system (WMoV-3) was also tested. This sample was chosen because it was previously proven to be more effective than $\mathrm{W}-\mathrm{V}-\mathrm{O}$ for both the glycerol ODH, leading to the maximum acrylic acid yield of 50\%, and the selective oxidation of acrolein to acrylic acid. This behavior was attributed to its higher acidity and better redox properties that allowed to dehydrate glycerol more efficiently and were responsible for a faster oxidation of the intermediately formed acrolein into acrylic acid and an easier desorption of the latter molecule from the catalyst surface [28]. Moreover, only a few papers regarding the gas phase oxidation of PAL to PAC are present in the 
literature, and the most effective catalyst so far reported is a system based on a Mo-V-O mixed oxide (hence containing both $\mathrm{V}$ and Mo as redox elements), which is typical catalyst for the gas phase oxidation of acrolein to acrylic acid $[17,18]$.

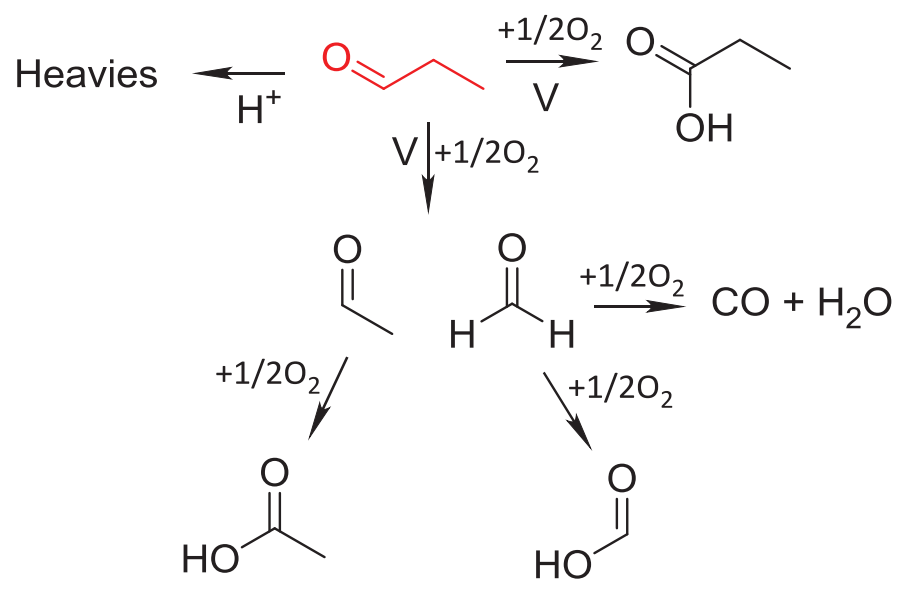

Scheme 5. Conversion of PAL with WV-1 catalyst.

Figure 4 shows the results of reactivity experiments with WMoV-3 catalyst. Indeed, the higher acid properties of the catalyst could be beneficial for the dehydration step of the whole process enhancing the formation rate of PAL from 1,2-PD, as it happens with glycerol [28]. However, despite the good premises, a very low yield into PAC was observed also in this case, still with a maximum value of $10 \%$ at the temperature of $240-260^{\circ} \mathrm{C}$. In contrast with WV-1, 1,2-PD conversion was complete in the whole range of temperature investigated. However, apart from this, this catalyst showed a catalytic behavior very similar to that one shown by WV-1. Dioxolanes formed in remarkable amounts at the lower temperatures, and their yield decreased along with an increase of temperature mainly in favor of the aldehydes (PAL and acetaldehyde). Yield to aldehydes decreased when the temperature was raised, whereas, on the other hand, acetic acid and carbon oxides increased, becoming the main reaction products for temperatures higher than $280^{\circ} \mathrm{C}$. Conversely, PAC always was a 
minor reaction product. Also in this case, it is interesting to highlight the fact that when glycerol was used as a reactant under the same reaction conditions, the yield to acrylic acid was $31 \%$, with acetaldehyde and acetic acid always showing very low yields [28].

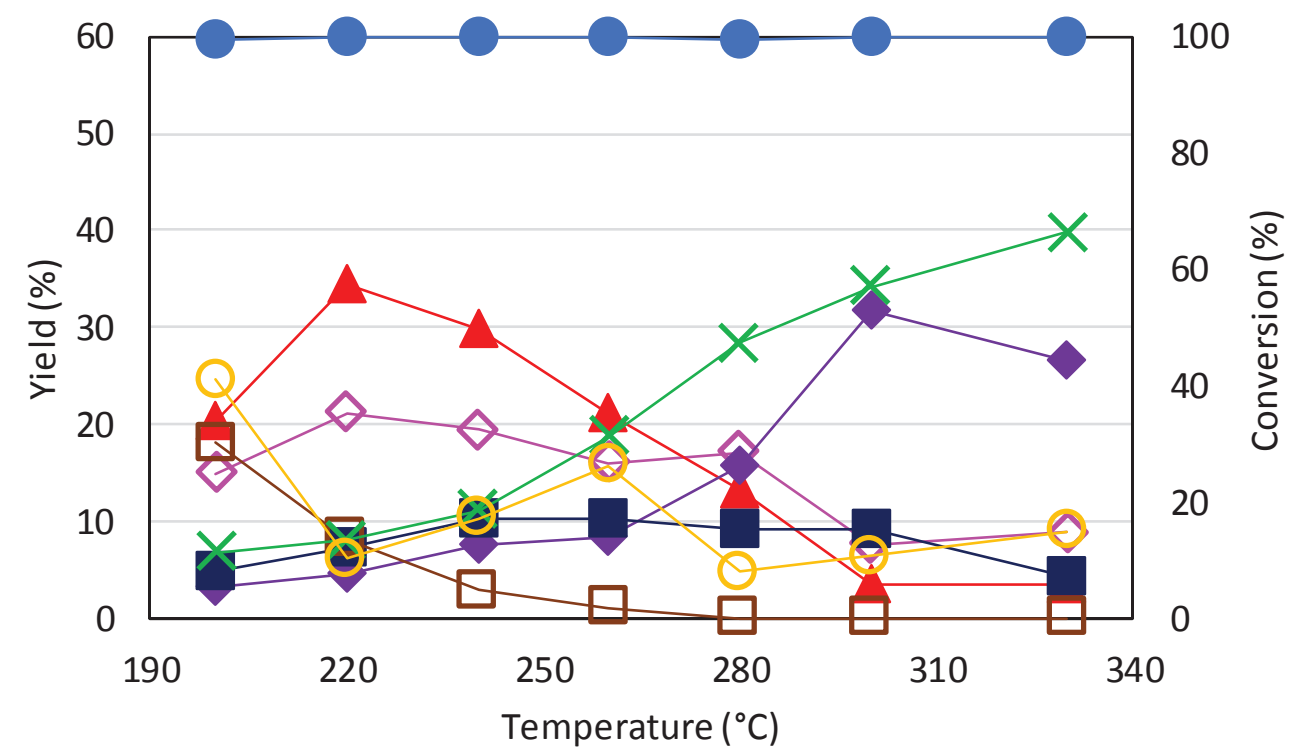

Figure 4. 1,2-PD conversion as a function of temperature with WMoV-3. Symbols: 1,2-PD conversion $(\bullet)$, PAL $(\boldsymbol{\Delta})$, dioxolanes $(\square)$, acetaldehyde $(\diamond)$, acetic acid $(\diamond)$, PAC $(\square)$ and carbon loss $(\circ), \mathrm{CO}_{\mathrm{x}}(\mathrm{X})$. Reaction conditions: feed composition (mol\%) 1,2-PD/O $/ \mathrm{O}_{2} \mathrm{O} / \mathrm{N}_{2}=2 / 4 / 40 / 54$; residence time $=0,01$ $\mathrm{g}^{*} \min / \mathrm{ml}$.

When PAL was fed (Figure S3), a higher PAC selectivity of $55 \%$ and a maximum yield of $29 \%$ were obtained at the temperature of $240^{\circ} \mathrm{C}$, together with a lower amount of heavy compounds, acetaldehyde and acetic acid, in the range between 240 and $280^{\circ} \mathrm{C}$. Then, a further increase of temperature up to $300^{\circ} \mathrm{C}$ led to a decrease of PAC selectivity, mainly in favor of acetic acid.

Overall, it emerges that the HTB catalysts appear to be efficient in promoting the selective oxidation of PAL into PAC for lower reaction temperatures (240$260^{\circ} \mathrm{C}$ ), whereas upon increasing the temperature, the formation of acetaldehyde, acetic acid and carbon oxides increasingly prevailed over 
selective oxidation to PAC. Despite this fact, the whole ODH reaction cannot be efficiently performed in the range of temperatures $240-260^{\circ} \mathrm{C}$. Therefore, reactivity experiments suggest that for HTB catalysts there might be a loss of selectivity to PAC due to some undesired reactions occurring directly on 1,2PD. This loss of selectivity might be ascribed in part to the formation of dioxolanes, by condensation of 1,2-PD and intermediate PAL (however, occurring only at lower temperatures), and in part to the formation of acetaldehyde, and hence acetic acid, deriving from the oxidative cleavage of 1,2-PD itself.

In order to confirm the hypothesized reaction scheme for 1,2-PD transformation on HTB oxides, we investigated the catalytic behavior of WMoV-3 as a function of contact time, under isothermal conditions $\left(240^{\circ} \mathrm{C}\right)$. The results are shown in Figure 5.

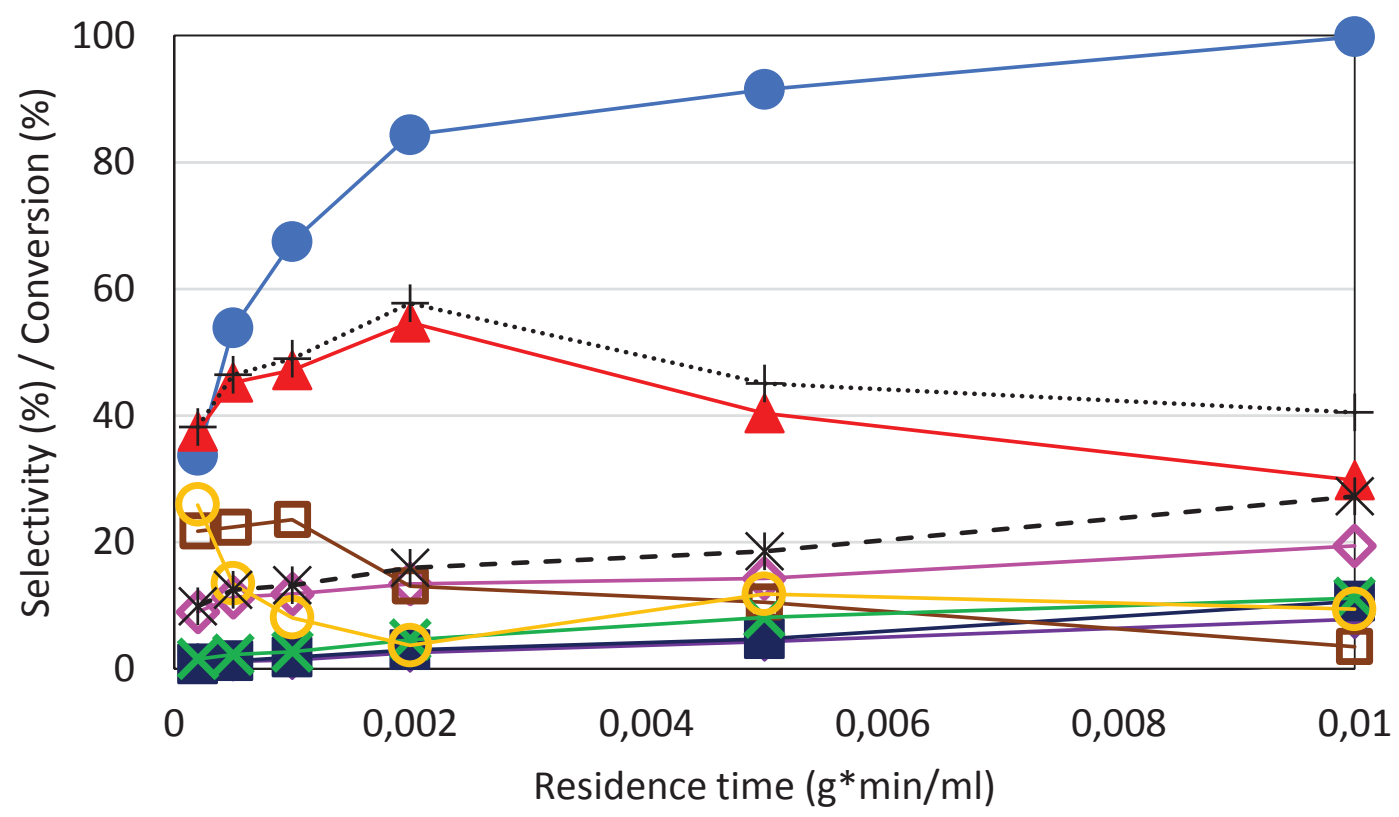

Figure 5. 1,2-PD conversion as a function of $\mathrm{W} / \mathrm{F}$ with $\mathrm{WMoV}-3$ at the temperature of $240^{\circ} \mathrm{C}$ and feed composition $(\mathrm{mol} \%)=1,2-\mathrm{PD} / \mathrm{O}_{2} / \mathrm{H}_{2} \mathrm{O} / \mathrm{N}_{2}=$

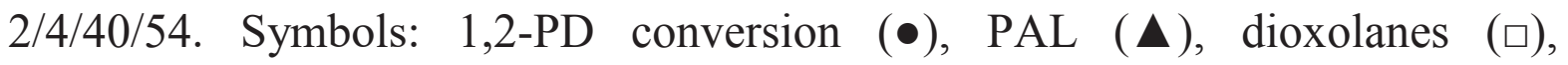
acetaldehyde $(\diamond)$, acetic acid $(\diamond)$, PAC $(\bullet), \mathrm{CO}_{\mathrm{x}}(\mathrm{X})$, carbon loss $(\circ)$, PAL + propionic acid $(+)$ and acetaldehyde + acetic acid $(*)$. 
PAL, dioxolanes and acetaldehyde appeared to be kinetically primary products, since their selectivity was higher than zero when extrapolated at nil residence time. PAL and dioxolanes also were intermediate compounds, in fact for both compounds selectivity declined upon increasing residence time. PAL selectivity first increased, reaching a maximum for $\mathrm{W} / \mathrm{F} 0,002 \mathrm{~g} * \mathrm{~min} / \mathrm{ml}$, and then it started to decrease mainly in favor of oxidation products. PAL initial increase can reasonably be attributed to dioxolanes selectivity decline: supposedly, for low 1,2-PD conversion, PAL can rapidly react with unconverted 1,2-PD by means of reversible condensation to form the cyclic acetal. However, consecutive reactions involving the intermediate PAL (and also 1,2-PD) can shift the equilibrium towards the reagents leading to a decrease of dioxolanes selectivity. Acetaldehyde selectivity kept increasing with residence time and this behavior could be explained by taking into account two contributions: acetaldehyde deriving from 2,4-methyl-dioxolane (generated by the reversible condensation of unconverted 1,2-PD and acetaldehyde itself, the latter deriving from 1,2-PD oxidative cleavage) and, in minor amount, from the oxidative cleavage of intermediate PAL. PAC, acetic acid and carbon oxides appeared to be secondary and final products, since their selectivity was higher than zero when extrapolated at nil residence time and then increased. In theory, acetaldehyde might also derive from propionic acid C-C scission, even if this experiment does not support this hypothesis.

In order to verify that there was no significant contribution of PAC cleavage, an experiment feeding PAL was also performed (Figure S4). Results are consistent with the kinetic study performed by feeding 1,2-PD. Indeed, PAC selectivity did not decrease in favor of other products.

Overall, these kinetic studies confirm that acetaldehyde may generate directly from 1,2-PD, supposedly by means of an oxidative cleavage reaction, promoted by the $\mathrm{V}$ redox sites of the catalyst. The latter reaction thus competes with 1,2- 
PD dehydration into PAL, catalysed by the acid sites of the oxide, and is responsible for the loss of selectivity into PAC.

In order to clarify how 1,2-PD oxidative cleavage is influenced by temperature, another experiment in function of contact time was performed with WMoV-3 at $300^{\circ} \mathrm{C}$ (Figure S5). In particular, the aim of this experiment was to confirm that acetaldehyde does not only derive from 1,2-PD but also from the cleavage of the intermediate PAL, and that temperature may affect the relative contribution of the two reactions.

By extrapolating the acetaldehyde selectivity at nil residence time for the two experiments, at $300^{\circ} \mathrm{C}$ (Figure S5) it appears to be higher than that obtained at $240^{\circ} \mathrm{C}$ (Figure 5) (about 20\% vs 10\%). However, it must be considered that at $240^{\circ} \mathrm{C}$ the formation of 2,4-methyl-1,3-dioxolane, deriving from the acetalization of unconverted 1,2-PD with acetaldehyde formed by 1,2-PD oxidative cleavage, was also observed for lower residence times, whereas at $300^{\circ} \mathrm{C}$ this compound did not form. Therefore, this latter result suggests that 1,2-PD oxidative cleavage might be influenced by temperature to a lesser extent compared to PAL. Indeed, when the conversion of PAL was studied in function of temperature (Figure S3), the selectivity to acetaldehyde + acetic acid was found to increase from $7 \%$ at $240^{\circ} \mathrm{C}$ to $30 \%$ at $300^{\circ} \mathrm{C}$. From experiments performed at $300^{\circ} \mathrm{C}$, the kinetic relationship between acetic acid and acetaldehyde also was clear, with acetic acid being a secondary product deriving from acetaldehyde oxidation. Indeed, acetic acid selectivity was null when extrapolated at nil residence time and then it increased with residence time, while acetaldehyde progressively decreased for W/F values higher than $0,005 \mathrm{~g} * \mathrm{~min} / \mathrm{ml}$.

Concluding, the experiments so far carried out are consistent with the overall reaction network reported in Scheme 6. The direct transformation of 1,2-PD into $\mathrm{PAC}$ is a very challenging process, since both the reactant and the intermediate 
PAL may undergo several reactions that finally decrease selectivity to the desired product.

In particular, HTB oxides were found to be efficient in the selective oxidation of PAL into PAC at $240-260{ }^{\circ} \mathrm{C}$ whereas, at higher temperatures, both the C-C cleavage of the aldehyde and the formation of carbon oxides prevailed over the oxidation to PAC. On the other hand, the lower was the reaction temperature, the higher the formation of compounds deriving from condensation reactions promoted by the acid sites of the catalysts.

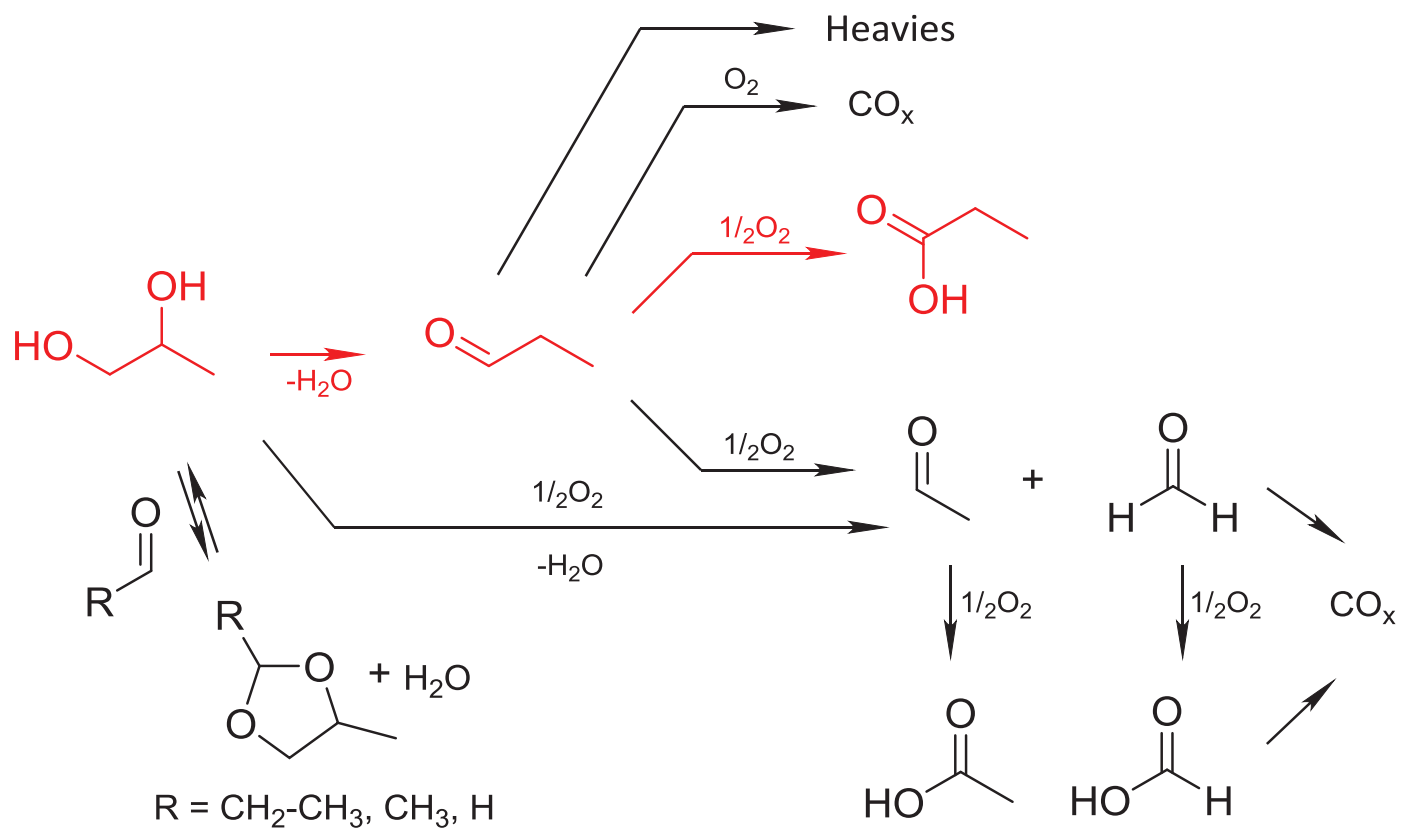

Scheme 6. Overall reaction network for 1,2-PD conversion on multifunctional HTB oxides. In red, the desired reaction pathway.

Referring to the first step of the process, the selectivity into PAL is limited by two competitive reactions: i) the formation of 2-ethyl-4-methyl-1,3-dioxolane, deriving from the acetalization of the aldehyde with unconverted 1,2-PD, promoted by the acid sites of the catalysts; ii) the $\mathrm{C}-\mathrm{C}$ oxidative cleavage of the glycol, that leads to the formation of $\mathrm{C}_{1}$ and $\mathrm{C}_{2}$ compounds, such as acetaldehyde, formaldehyde, acetic acid, formic acid and carbon oxides. 1,2-PD 
cleavage does not appear to be much sensitive to reaction temperature, whereas the formation of 2-ethyl-4-methyl-1,3-dioxolane can be reduced by increasing temperature and hence 1,2-PD conversion. However, by increasing the temperature, PAL cleavage and unselective oxidation started to prevail over the formation of PAC.

\subsection{About the mechanism of acetaldehyde formation}

A few hypotheses can be formulated to explain the formation of acetaldehyde. First, we took into account the possibility of formation of an acetone-like species adsorbed on the catalyst surface (Scheme 7). As previously shown, in the presence of an acid catalyst, acetone may generate from the elimination of the secondary hydroxyl group in 1,2-PD. Similar considerations can be made for glycerol ODH: the formation of acetaldehyde might derive from hydroxyacetone. On the other hand, the latter compound might also form by 1,2PD oxidation.

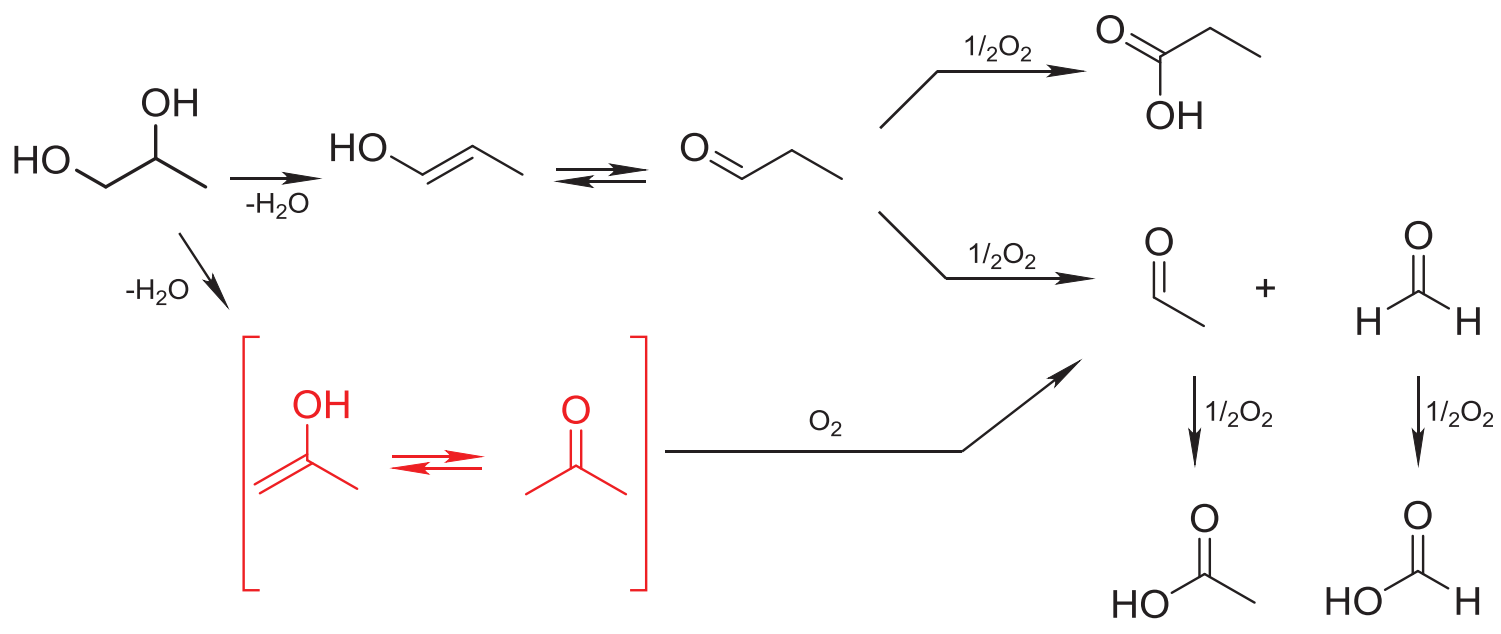

Scheme 7. Acetone or acetone-like specie as intermediates for the formation of acetaldehyde from 1,2-PD.

Therefore, a few reactivity experiments were carried out by feeding directly acetone (Table S2) and hydroxyacetone (Table S3) with WV-1 and WMoV-3 
catalysts. A very low acetone conversion was observed on both HTB oxides. Carbon oxides and acetic acid were the main reaction products whereas low selectivity to acetaldehyde was shown. These results suggest that acetone on HTB oxides might convert directly into acetic acid rather than to acetaldehyde, as already reported by Concepciòn et al. for propane and propylene oxidation on $\mathrm{V}$ and Mo- $\mathrm{V}$ based catalysts [33]. In conclusion, 1,2-PD oxidative cleavage does not appear to go through the generation of an acetone-like species as the main intermediate.

On the other hand, with hydroxyacetone an almost complete conversion was observed, together with a higher selectivity to acetaldehyde. Therefore, the formation of acetaldehyde, and hence acetic acid, might derive from the conversion of the intermediately formed hydroxyacetone. Hence, 1,2-PD and glycerol might share the same intermediate for the generation of acetaldehyde, and hence acetic acid, on HTB oxides, even if this species likely derives from different reaction pathways (i.e., dehydration from glycerol and oxidation from 1,2-PD).

Finally, pyruvaldehyde was also considered as a possible reaction intermediate; results of reactivity experiments carried out by feeding pyruvaldehyde are reported in Table S4.

Similarly to hydroxyacetone, pyruvaldehyde conversion was almost complete with formation of acetaldehyde, acetic acid and carbon oxides. Overall, it appears that both hydroxyacetone and pyruvaldehyde can be the precursors for the generation of acetaldehyde from 1,2-PD (but also from glycerol) on HTB oxides.

\subsection{Reactivity of $\mathrm{MoVW}-4$ mixed oxide with $\mathrm{Mo}_{5} \mathrm{O}_{14}$ structure.}

Finally, the catalytic behavior of a $\mathrm{Mo}-\mathrm{V}-\mathrm{W}$ mixed oxide with $\mathrm{Mo}_{5} \mathrm{O}_{14}$ structure, the catalyst for acrolein oxidation to acrylic acid, was investigated. Catalytic 
performance as a function of temperature is summarised in Figure 6. Also with this catalyst, the formation of dioxolanes gradually decreased while increasing temperature and conversion. This catalyst displayed very low yields to carbon oxides, which slightly increased while raising the temperature. Selectivity to both acetic and PAC, respectively deriving from acetaldehyde and PAL selective oxidation, progressively increased with temperature. However, PAC was a minor reaction product, with $10 \%$ maximum yield at $260^{\circ} \mathrm{C}$, and with acetaldehyde and acetic acid as the main reaction products. Results strongly suggest that also with MoVW-4, 1,2-PD easily underwent C-C cleavage, and this behavior can reasonably be explained by considering the weak acid properties of the material, not enough to promote 1,2-PD dehydration.

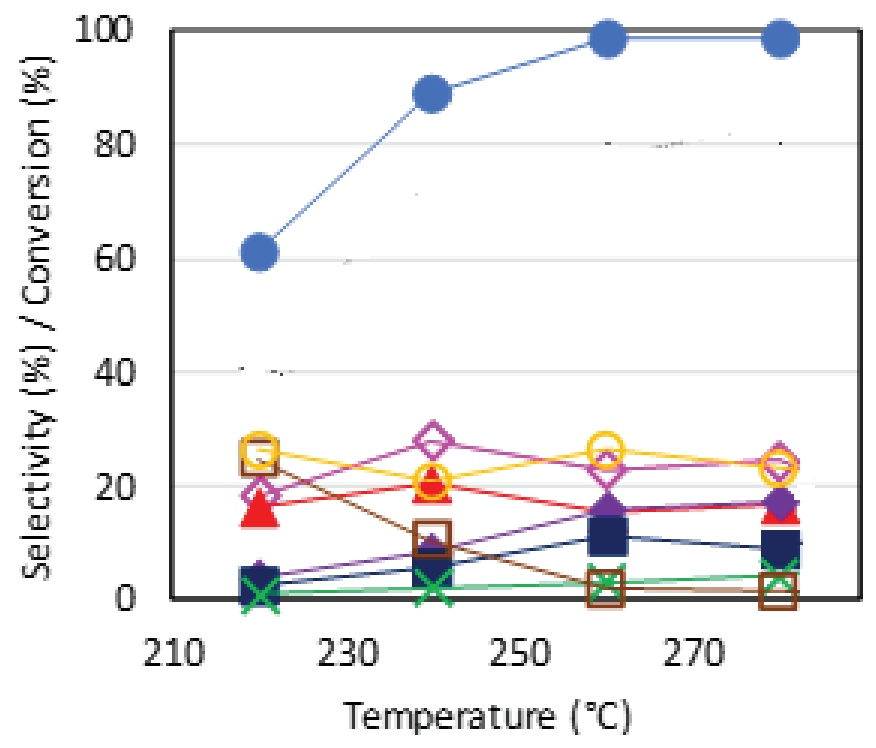

Figure 6. 1,2-PD conversion as a function of temperature with MoVW-4. Symbols: 1,2-PD conversion $(\bullet), \operatorname{PAL}(\boldsymbol{\Delta})$, acetaldehyde $(\diamond)$, acetic acid $(\diamond)$, PAC ( $\mathbf{\square})$, dioxolanes $(\square), \mathrm{CO}_{\mathrm{x}}(\mathrm{X})$, carbon loss (०). Reaction conditions: feed composition (mol\%) 1,2-PD/ $\mathrm{O}_{2} / \mathrm{H}_{2} \mathrm{O} / \mathrm{N}_{2}=2 / 4 / 40 / 54 ;$ residence time $=0,01$ $\mathrm{g}^{*} \min / \mathrm{ml}$.

Results of catalytic experiments carried out with PAL are shown in Figure S6. This catalytic system turned out to be more efficient than HTB for PAL oxidation into PAC, leading to the maximum yield of $45 \%$ at the temperature of 
$280^{\circ} \mathrm{C}$ and a selectivity of $70 \%$ (vs the maximum selectivity of $55 \%$ for W-MoV-O with HTB structure).

\subsection{FTIR spectra of adsorbed 1,2-PD}

The intermediate species involved in the oxidation of 1,2-PD on mixed oxide catalysts with different acid and/or redox properties have been studied by means of IR spectroscopy. Reference IR spectra of all possible reaction products adsorbed on catalysts have been acquired (see Figures S7 to S10), whereas the representative IR bands are compiled in Table S6.

On the other hand, the IR spectra of 1,2-propanediol co-adsorbed with $\mathrm{O}_{2}$ are shown in Figures 7 and 8, and they will be discussed in detail for each sample.
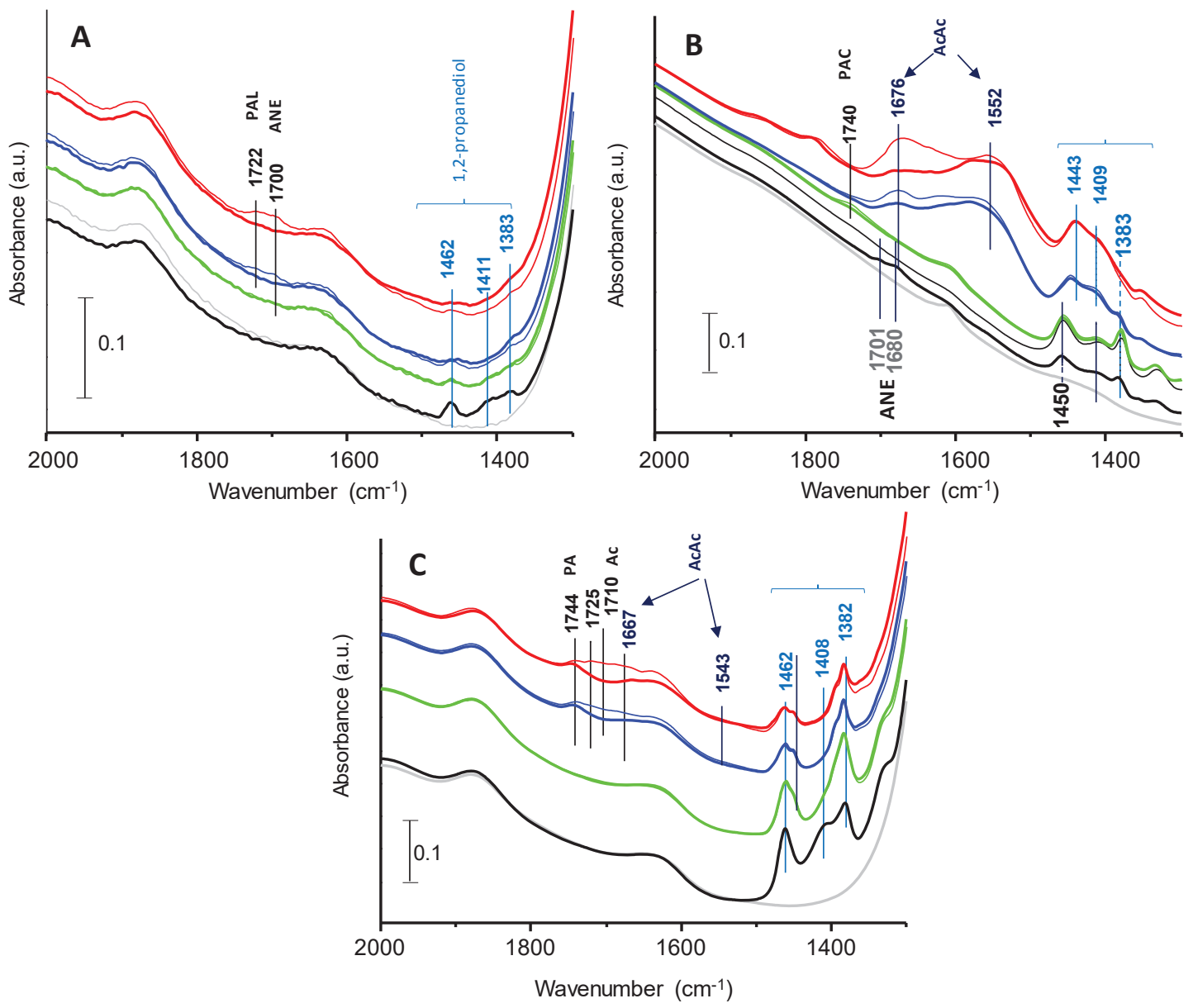

Figure 7. IR spectra of 0.5 mbar 1,2-PD co-adsorbed with $1.7 \mathrm{mbar}_{2}$ on samples: A) WNb-2; b) WV-1; and C) WVMo-3. Experiments were carried out 
PAL may undergo several reactions that finally decrease selectivity to the desired product.

In particular, HTB oxides were found to be efficient in the selective oxidation of PAL into PAC at $240-260{ }^{\circ} \mathrm{C}$ whereas, at higher temperatures, both the C-C cleavage of the aldehyde and the formation of carbon oxides prevailed over the oxidation to PAC. On the other hand, the lower was the reaction temperature, the higher the formation of compounds deriving from condensation reactions promoted by the acid sites of the catalysts.

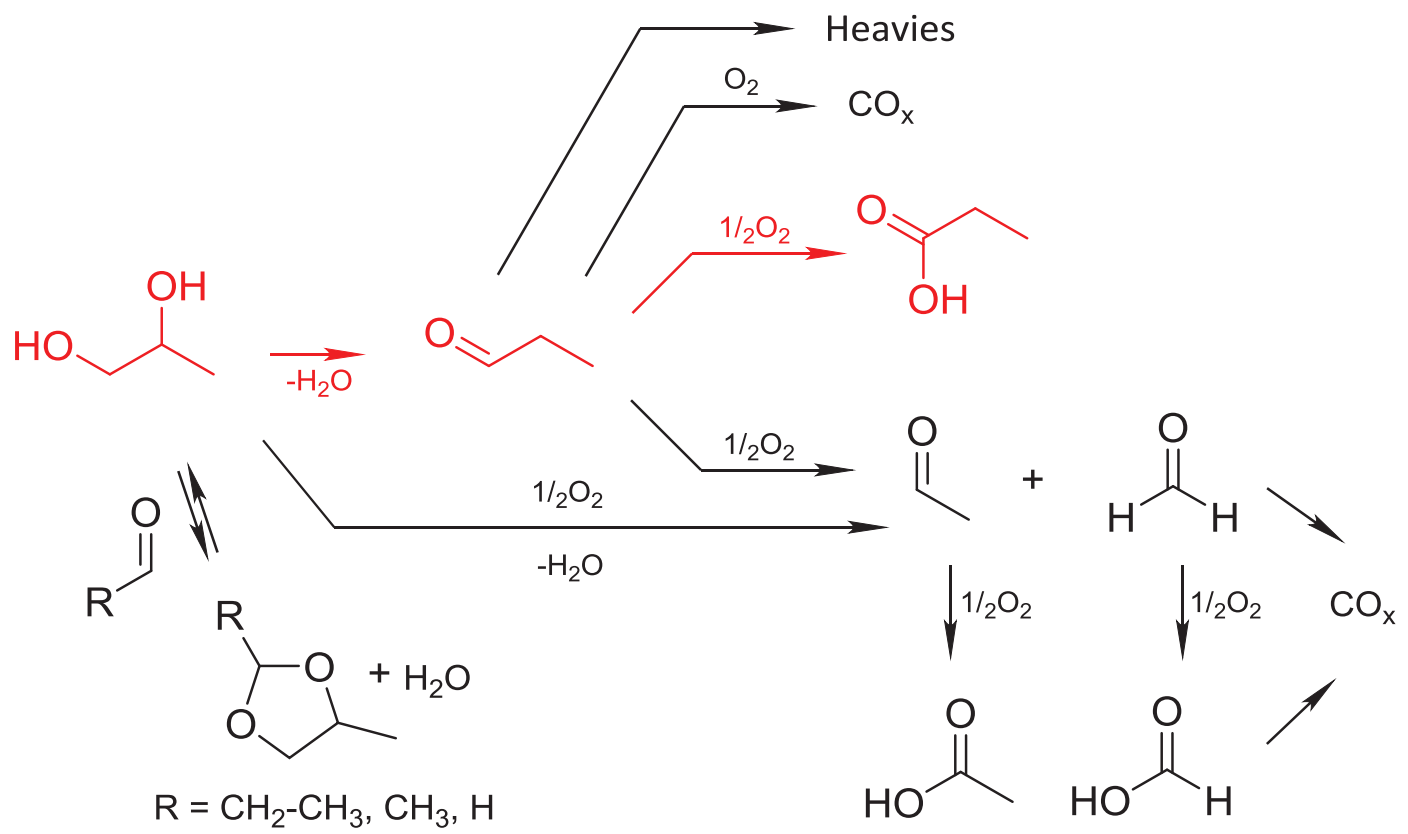

Scheme 6. Overall reaction network for 1,2-PD conversion on multifunctional HTB oxides. In red, the desired reaction pathway.

Referring to the first step of the process, the selectivity into PAL is limited by two competitive reactions: i) the formation of 2-ethyl-4-methyl-1,3-dioxolane, deriving from the acetalization of the aldehyde with unconverted 1,2-PD, promoted by the acid sites of the catalysts; ii) the $\mathrm{C}-\mathrm{C}$ oxidative cleavage of the glycol, that leads to the formation of $\mathrm{C}_{1}$ and $\mathrm{C}_{2}$ compounds, such as acetaldehyde, formaldehyde, acetic acid, formic acid and carbon oxides. 1,2-PD 
cleavage does not appear to be much sensitive to reaction temperature, whereas the formation of 2-ethyl-4-methyl-1,3-dioxolane can be reduced by increasing temperature and hence 1,2-PD conversion. However, by increasing the temperature, PAL cleavage and unselective oxidation started to prevail over the formation of PAC.

\subsection{About the mechanism of acetaldehyde formation}

A few hypotheses can be formulated to explain the formation of acetaldehyde. First, we took into account the possibility of formation of an acetone-like species adsorbed on the catalyst surface (Scheme 7). As previously shown, in the presence of an acid catalyst, acetone may generate from the elimination of the secondary hydroxyl group in 1,2-PD. Similar considerations can be made for glycerol ODH: the formation of acetaldehyde might derive from hydroxyacetone. On the other hand, the latter compound might also form by 1,2PD oxidation.

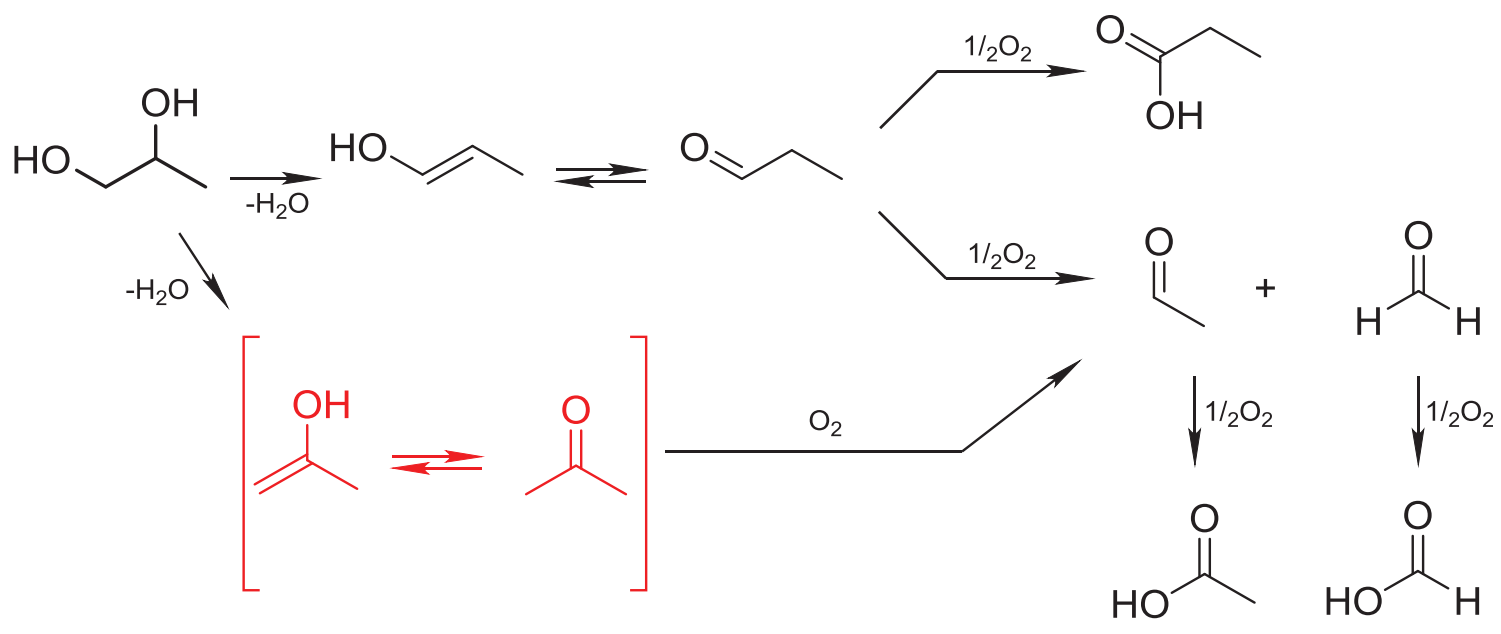

Scheme 7. Acetone or acetone-like specie as intermediates for the formation of acetaldehyde from 1,2-PD.

Therefore, a few reactivity experiments were carried out by feeding directly acetone (Table S2) and hydroxyacetone (Table S3) with WV-1 and WMoV-3 
catalysts. A very low acetone conversion was observed on both HTB oxides. Carbon oxides and acetic acid were the main reaction products whereas low selectivity to acetaldehyde was shown. These results suggest that acetone on HTB oxides might convert directly into acetic acid rather than to acetaldehyde, as already reported by Concepciòn et al. for propane and propylene oxidation on $\mathrm{V}$ and Mo- $\mathrm{V}$ based catalysts [33]. In conclusion, 1,2-PD oxidative cleavage does not appear to go through the generation of an acetone-like species as the main intermediate.

On the other hand, with hydroxyacetone an almost complete conversion was observed, together with a higher selectivity to acetaldehyde. Therefore, the formation of acetaldehyde, and hence acetic acid, might derive from the conversion of the intermediately formed hydroxyacetone. Hence, 1,2-PD and glycerol might share the same intermediate for the generation of acetaldehyde, and hence acetic acid, on HTB oxides, even if this species likely derives from different reaction pathways (i.e., dehydration from glycerol and oxidation from 1,2-PD).

Finally, pyruvaldehyde was also considered as a possible reaction intermediate; results of reactivity experiments carried out by feeding pyruvaldehyde are reported in Table S4.

Similarly to hydroxyacetone, pyruvaldehyde conversion was almost complete with formation of acetaldehyde, acetic acid and carbon oxides. Overall, it appears that both hydroxyacetone and pyruvaldehyde can be the precursors for the generation of acetaldehyde from 1,2-PD (but also from glycerol) on HTB oxides.

\subsection{Reactivity of $\mathrm{MoVW}-4$ mixed oxide with $\mathrm{Mo}_{5} \mathrm{O}_{14}$ structure.}

Finally, the catalytic behavior of a $\mathrm{Mo}-\mathrm{V}-\mathrm{W}$ mixed oxide with $\mathrm{Mo}_{5} \mathrm{O}_{14}$ structure, the catalyst for acrolein oxidation to acrylic acid, was investigated. Catalytic 
performance as a function of temperature is summarised in Figure 6. Also with this catalyst, the formation of dioxolanes gradually decreased while increasing temperature and conversion. This catalyst displayed very low yields to carbon oxides, which slightly increased while raising the temperature. Selectivity to both acetic and PAC, respectively deriving from acetaldehyde and PAL selective oxidation, progressively increased with temperature. However, PAC was a minor reaction product, with $10 \%$ maximum yield at $260^{\circ} \mathrm{C}$, and with acetaldehyde and acetic acid as the main reaction products. Results strongly suggest that also with MoVW-4, 1,2-PD easily underwent C-C cleavage, and this behavior can reasonably be explained by considering the weak acid properties of the material, not enough to promote 1,2-PD dehydration.

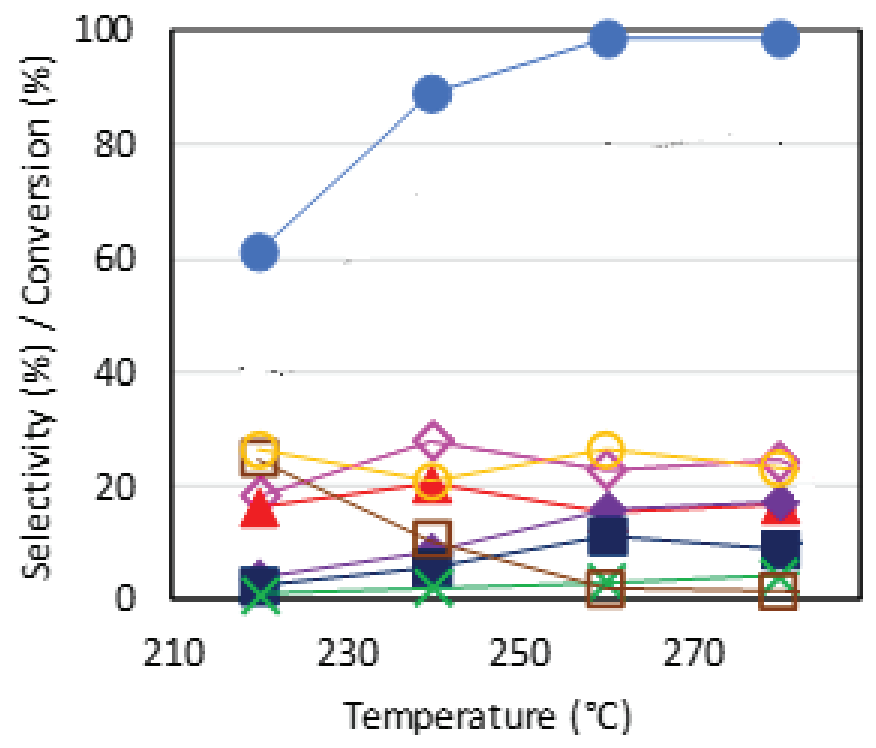

Figure 6. 1,2-PD conversion as a function of temperature with MoVW-4. Symbols: 1,2-PD conversion $(\bullet), \operatorname{PAL}(\boldsymbol{\Delta})$, acetaldehyde $(\diamond)$, acetic acid $(\diamond)$, PAC ( $\mathbf{\square})$, dioxolanes $(\square), \mathrm{CO}_{\mathrm{x}}(\mathrm{X})$, carbon loss (०). Reaction conditions: feed composition (mol\%) 1,2-PD/ $\mathrm{O}_{2} / \mathrm{H}_{2} \mathrm{O} / \mathrm{N}_{2}=2 / 4 / 40 / 54 ;$ residence time $=0,01$ $\mathrm{g}^{*} \min / \mathrm{ml}$.

Results of catalytic experiments carried out with PAL are shown in Figure S6. This catalytic system turned out to be more efficient than HTB for PAL oxidation into PAC, leading to the maximum yield of $45 \%$ at the temperature of 
$280^{\circ} \mathrm{C}$ and a selectivity of $70 \%$ (vs the maximum selectivity of $55 \%$ for W-MoV-O with HTB structure).

\subsection{FTIR spectra of adsorbed 1,2-PD}

The intermediate species involved in the oxidation of 1,2-PD on mixed oxide catalysts with different acid and/or redox properties have been studied by means of IR spectroscopy. Reference IR spectra of all possible reaction products adsorbed on catalysts have been acquired (see Figures S7 to S10), whereas the representative IR bands are compiled in Table S6.

On the other hand, the IR spectra of 1,2-propanediol co-adsorbed with $\mathrm{O}_{2}$ are shown in Figures 7 and 8, and they will be discussed in detail for each sample.
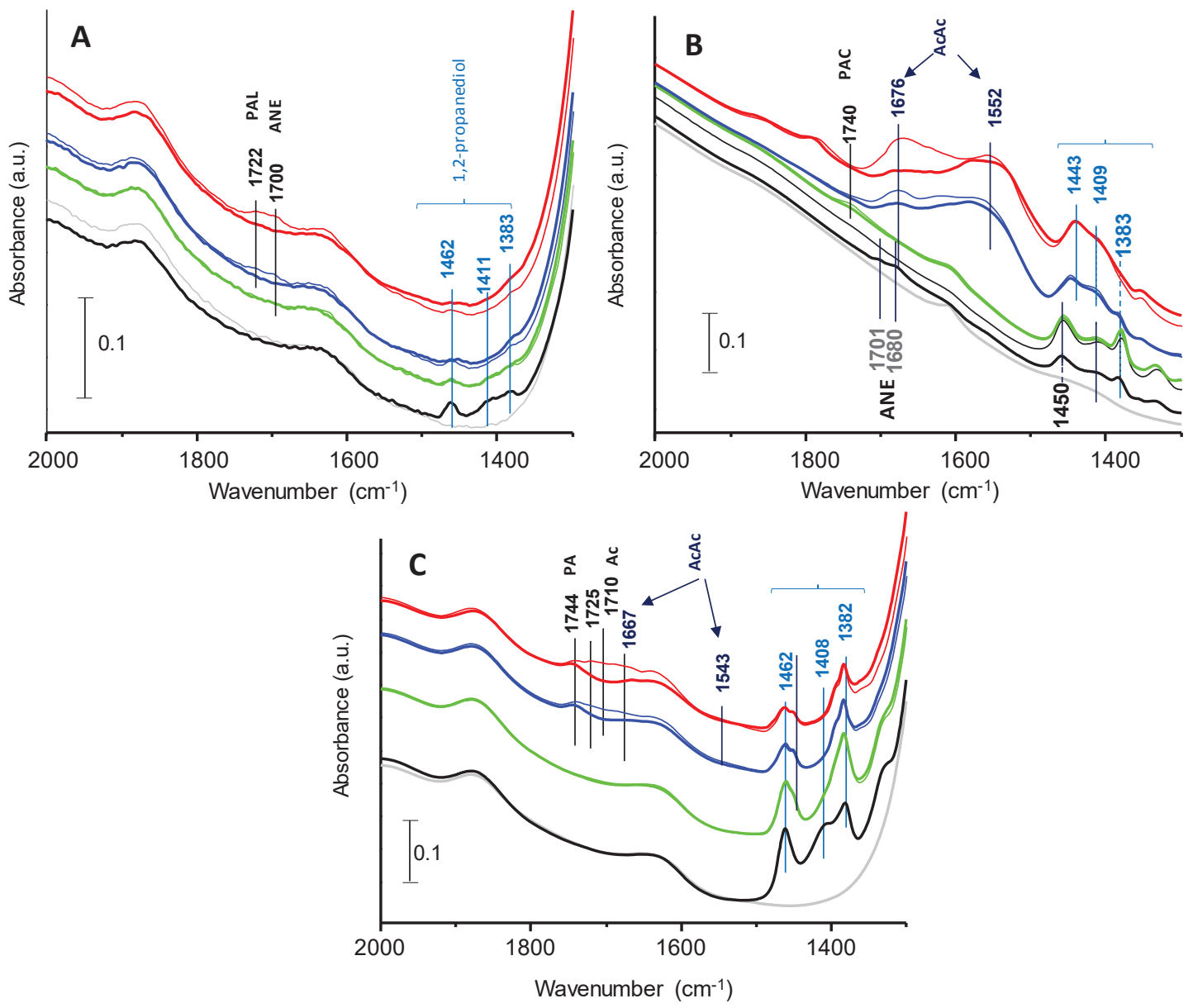

Figure 7. IR spectra of 0.5 mbar 1,2-PD co-adsorbed with $1.7 \mathrm{mbar}_{2}$ on samples: A) WNb-2; b) WV-1; and C) WVMo-3. Experiments were carried out 